\title{
A Convenient Synthesis of C-22 and C-25 Stereoisomers of Cephalostatin North 1 Side Chain from Spirostan Sapogenins
}

\section{Carmen Betancort,Raimundo Freireț,Ine'sPe'rez-Mart'In,tThiemy Prang'e,sand Ernesto Su'arez ${ }^{\star \ddagger}$}

Instituto de Productos Naturales y Agrobiolog'za del C.S.I.C.,

Carretera de La Esperanza 3, 38206 La Laguna, Tenerife, Spain,

Departamento de Qu' Imica Orga'nica, UniVersidad de La Laguna, Tenerife, Spain, and LURE, UniVersite' Paris-Sud, Paris, 91405 Orsay Cedex, France

esuarez@ipna.csic.es

Received January 18, 2002

\section{ABSTRACT}

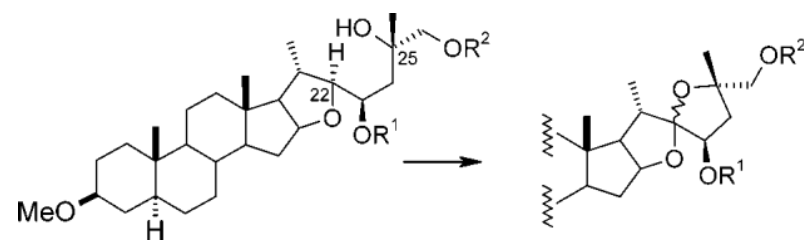

A simpletransformationof the eight-carbon side chain of a natural spirostan sapogenin into the cephalostatin north 1 spiroketal moietyis described. This methodology, based on an intramolecular hydrogen abstraction reaction promoted by alkoxy radicals, permits the synthesis of C-22 and C-25 stereoisomersof the dioxaspiro[4.4]nonanecephalostatinring system. The acid-catalyzed isomerizationof the spirocenter in the different isomersisstudied.

Several marine alkaloid cephalostatins ${ }^{1}$ and ritterazines ${ }^{2}$ are among the most potent cytotoxins ever isolated from a natural source. ${ }^{3}$ They are formed by two steroidal units linked through a pyrazine ring involving $\mathrm{C} 2$ and $\mathrm{C} 3$ of each monomeric unit. In most of the cephalostatins (17 out of 19) the north steroidal eight-carbon side chain has been transformed into a polyoxygenated $(2 S, 4 R, 5 S, 9 S)$-2-hy-

$\dagger$ Universidad de La Laguna.

$\$$ Instituto de Productos Naturales y Agrobiolog'́1a.

$\S$ Universite' Paris-Sud.

(1) (a) Pettit, G. R.; Inoue, M.; Kamano, Y.; Herald, D. L.; Arm, C.; Dufresne, C.; Christie, N. D.; Schmidt, J. M.; Doubek, D. L.; Krupa, T. S. J. Am. Chem. Soc. 1988, 110, 2006-2007. (b) Recent publication: Pettit, G. R.; Tan, R.; Xu, J.-P.; Ichihara, Y.; Williams, M. D.; Boyd, M. R. J. Nat. Prod. 1998, 61, 955-958 and references therein.

(2) Recent publication: Fukuzawa, S.; Matsunaga, S.; Fusetani, N. J. Org. Chem. 1997, 62, 4484-4491 and references therein.

(3)Pettit, G. R.; Xu, J.-P.; Williams, M. D.; Christie, N. D.; Doubek, D. L.; Schmidt, J. M.; Boyd, M. R. J. Nat. Prod. 1994, 57, 52-63. droxymethyl-2,9-dimethyl-1,6-dioxaspiro[4.4]nonan-4-ol substructure (see, for example, cephalostatin 1).

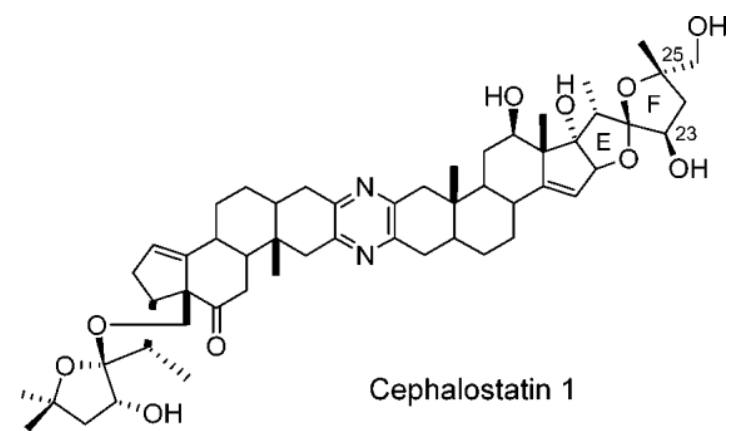

Their unique structure and biological activity have made them an important synthetic target. The syntheses of several 
of these natural products and analogues have been achieved, ${ }^{4}$ but despite efforts by several research groups, the mechanism of action of these compounds remains unknown. ${ }^{5}$

Taking into account the SAR correlation of cephalostatins and OSW-1, 6 a related cholestane glycoside isolated from a terrestrial plant, it was hypothesized that the active intermediate might be an oxycarbenium ion located at rings $\mathrm{E}$ or $\mathrm{F}$ and originated by opening of the dioxaspiro grouping. ${ }^{7} \mathrm{We}$ can deduce from this that the stereochemistries at C-22, C23 , and $\mathrm{C}-25$, which doubtless have a strong influence on the stability of the dioxaspiro[4.4]nonane system, may also influence the activity of cephalostatins.

With these ideas in mind, we decided to develop a simple methodology to permit the synthesis of all possible isomers of this system by modification of the steroidal side chain of a spirostan sapogenin, the key step being an intramolecular hydrogen abstraction reaction (IHA) promoted by alkoxy radicals. ${ }^{8}$ In previous papers from this laboratory, we have demonstrated the utility of IHA reactions in the synthesis of dioxaspiro[4.4]nonane ring systems in the carbohydrate field. ${ }^{9}$

The synthesis starts with 3-methoxy-23-oxotigogenin (2) (Scheme 1) prepared using a previously described procedure by oxidation of 3-methoxytigogenin (1) with $\mathrm{NaNO}_{2} / \mathrm{BF}_{3}$, $\mathrm{Et}_{2} \mathrm{O} .{ }^{10}$ The reduction of 2 with $\mathrm{L}-\mathrm{Selectride}$ gave a mixture of alcohols 3 and 4 (72\%, 1.7:1) from which the alcohol 3 with the correct natural orientation $(23 R)$ could be obtained in moderate yield. The reduction of $\mathbf{2}$ with $\mathrm{NaBH}_{4}$ afforded preferentially the non-natural isomer 4 (91\%, 19:1). In these preliminary studies we decided to continue with the natural diastereoisomeric alcohol 3. The regio- and stereoselective opening reaction of the tigogenin dioxaspiro[5.4]decane system present in $\mathbf{3}$ was accomplished with $\mathrm{Ph}_{2} \mathrm{SiH}_{2} / \mathrm{TiCl}_{4}$ to give diol 5 in $67 \%$ yield. ${ }^{11}$

(4)(a) Dro"gemu"ller, M.; Jautelat, R.; Winterfeld, E. Angew. Chem., Int. Ed. Engl. 1996, 35, 1572-1574. (b) LaCour, T. G.; Guo, C.; Bhandaru, S.; Boyd, M. R.; Fuchs, P. L. J. Am. Chem. Soc. 1998, 120, 692-707. (c) Dro"gemu"ller, M.; Flessner, T.; Jautelat, R.; Scholz, U.; Winterfeld, E. Eur. J. Org. Chem. 1998, 2811-2831. (d) Kim, S.; Sutton, S. C.; Guo, C.; LaCour, T. G.; Fuchs, P. L. J. Am. Chem. Soc. 1999, 121, 2056-2070. (e) Jeong, J. U.; Guo, C.; Fuchs, P. L. J. Am. Chem. Soc. 1999,121, 2071 2084. (f) For a short review, see: Ganesan, A. Angew. Chem., Int. Ed. Engl. 1996, $35,611-615$.

(5) LaCour, T. G.; Guo, C.; Boyd, M. R.; Fuchs, P. L. Org. Lett. 2000, 2, 33-36.

(6)(a) Guo, C.; Fuchs, P. L. Tetrahedron Lett. 1998, 39, 1099-1102. (b) Deng, S.; Yu, B.; Lou, Y.; Hui, Y. J. Org. Chem. 1999, 64, 202-208. (c) Yu, W.; Jin, Z. J. Am. Chem. Soc. 2001, 123, 3369-3370.

(7) (a) Guo, C.; LaCour, T. G.; Fuchs, P. L. Bioorg., Med. Chem. Lett. 1999, 9, 419-424. (b) Guo, C.; Fuchs, P. L. Tetrahedron. Lett. 1998,39, 1099-1102.

(8)(a) Majetich, G. Tetrahedron 1995, 51, 7095-7129. (b) Feray, L.; Kuznetsov, N.; Renaud, P. In Hydrogen Atom Abstraction; Renaud, P., Sibi, M. P., Eds.; Radicals in Organic Synthesis, Vol. 2. Wiley-VCH: Weinheim, 2001; pp 246-278. (c) Robertson, J.; Pillai, J.; Lush, R. K. Chem. Soc. ReV. 2001,30,94-103.

(9) (a) Mart' in, A.; Salazar, J. A.; Sua'rez, E. J. Org. Chem. 1996, 61, 3999-4006. (b) Dorta, R. L.; Mart'in, A.; Salazar, J. A.; Suárez, E.; Prange', T. J. Org. Chem. 1998, 63, 2251-2261.

(10) (a) Barton, D. H. R.; Sammes, P. G.; Taylor, M. V.; Werstiuk, E. J. Chem. Soc. C 1970, 1977-1981. (b) Gonza'lez, A. G.; Freire, R.; Garc'iaEstrada, M. G.; Salazar, J. A.; Sua'rez, E. Tetrahedron 1972, 28, 12891297. (c) Gonza'lez, A. G.; Freire, R.; Garc'ia-Estrada, M. G.; Salazar, J. A.; Sua'rez,E. Anal. Chim. 1971, 67, 903-905.

(11) Oikawa, M.; Oikawa, H.; Ichihara, A. Tetrahedron 1995, 51,6237-

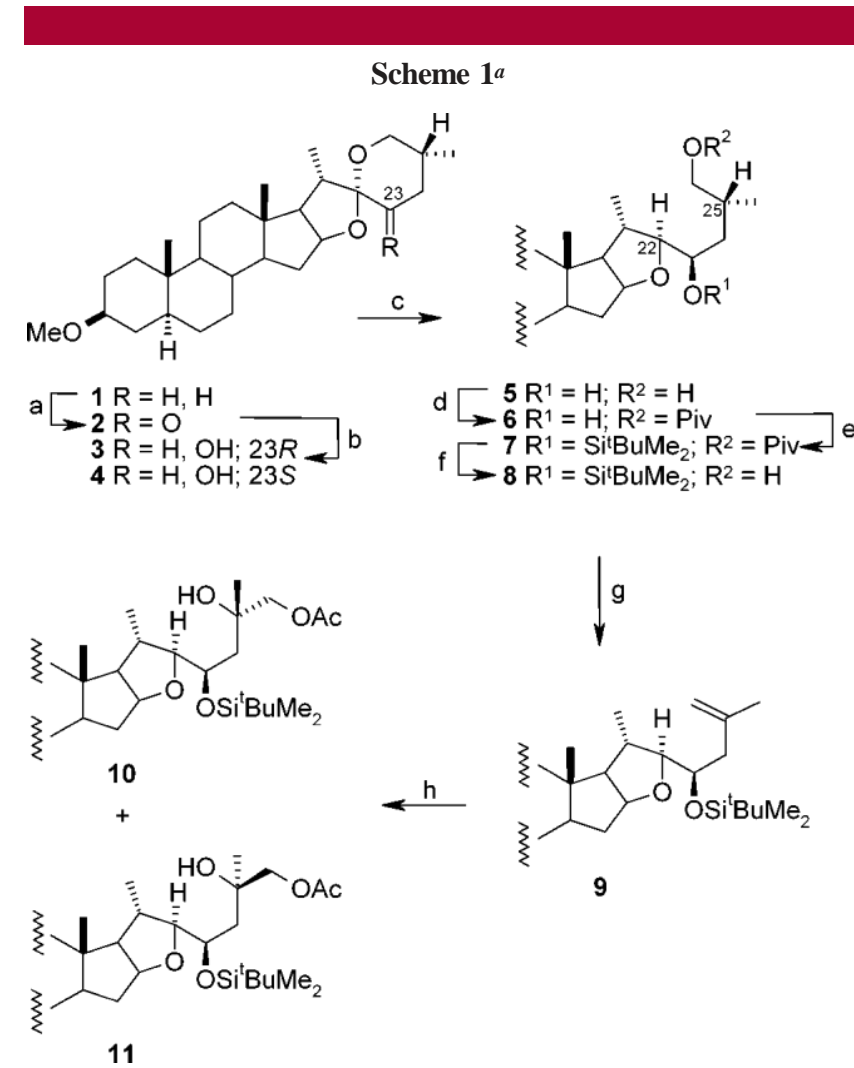

${ }^{a}$ Reagent and conditions: (a) $\mathrm{NaNO}_{2}, \mathrm{BF}_{3}, \mathrm{Et}_{2} \mathrm{O}, \mathrm{AcOH}, \mathrm{rt}, 1 \mathrm{~h}$, $68 \%$; (b) $\mathrm{NaBH}_{4}, \mathrm{EtOH}, \mathrm{rt}, 1$ h, $91 \%$ (3/4 ratio 5:95) or L-Selectride, THF, $-20{ }^{\circ} \mathrm{C}, 2 \mathrm{~h}, 72 \%$ (3/4 ratio 63:37); (c) $\mathrm{Ph}_{2} \mathrm{SiH}_{2}, \mathrm{TiCl}_{4}$, $\mathrm{CH}_{2} \mathrm{Cl}_{2}$, - $20{ }^{\circ} \mathrm{C}, 1.5 \mathrm{~h}, 67 \%$; (d) pivaloyl chloride, $\mathrm{Py}, \mathrm{CH}_{2} \mathrm{Cl}_{2}$, rt, 24 h, 96\%; (e) ${ }^{t} \mathrm{BuMe}_{2} \mathrm{SiOTf}, \mathrm{CH}_{2} \mathrm{Cl}_{2}, \mathrm{Et}_{3} \mathrm{~N}, \mathrm{rt}, 3 \mathrm{~h}, 81 \%$; (f) $\mathrm{KOH}$, $\mathrm{MeOH}, 50{ }^{\circ} \mathrm{C}, 24 \mathrm{~h}, 92 \%$; (g) (i) $o-\mathrm{NO}_{2} \mathrm{PhSeCN}, n-\mathrm{Bu} 3 \mathrm{P}, \mathrm{THF}, \mathrm{rt}$, $0.5 \mathrm{~h}, 99 \%$, (ii) $\mathrm{H}_{2} \mathrm{O}_{2}$, THF, rt, $3 \mathrm{~h}, 92 \%$; (h) (i) $\mathrm{OsO}_{4}, \mathrm{Py}, \mathrm{CH}_{2} \mathrm{Cl}_{2}$, rt, 1.5 h, (ii) $\mathrm{Ac}_{2} \mathrm{O}$, py, rt, $99 \%$ (10/11 ratio 1:2).

Conversion of $\mathbf{5}$ to the monoprotected primary alcohol $\mathbf{8}$ was accomplished by a protection-deprotection sequence involving formation of the primary pivalate $6(96 \%)$, silylation with TBSOTf $(81 \%)$, and hydrolysis of pivalate 7 with $\mathrm{KOH} / \mathrm{MeOH}$ (92\%). Nitrophenylselenenylation of the primary alcohol in $\mathbf{8}$ followed by oxidative elimination furnished alkene 9 in $92 \%$ yield. Osmylation of the double bond and subsequent acetylation afforded tertiary alcohols $\mathbf{1 0}$ and $\mathbf{1 1}(99 \%, 1: 2) .12$

The IHA reaction was carried out by separately treating compounds $\mathbf{1 0}$ and $\mathbf{1 1}$ with (diacetoxyiodo)benzene and iodine under irradiation with two $80 \mathrm{~W}$ tungsten-filament lamps at $50{ }^{\circ} \mathrm{C}$. Alcohol $\mathbf{1 0}$ afforded a mixture of the dioxaspirocycles $\mathbf{1 2}$ and $\mathbf{1 3}(83 \%, 28: 72)$ while alcohol $\mathbf{1 1}$ gave compounds $\mathbf{1 7}$ and $\mathbf{1 8}(83 \%, 33: 67)$ (Scheme 2). The desired diols 14, 15 and 19, 20 (Scheme 2) were subsequently obtained by hydrolysis of the silyl and acetate protective groups, the structures of which were determined by extensive ${ }^{1} \mathrm{H}$ and ${ }^{13} \mathrm{C}$ NMR $1 \mathrm{D}$ and 2D studies including DEPT, COSY, HMBC, HSQC, and NOESY experiments and confirmed by $\mathrm{X}$-ray crystallography analysis of compounds $\mathbf{1 5}$ and 20. The

(12) For studies on the diastereoselective osmylation of a related olefin see: refs $4 b, c$. 
Scheme 2. IHA Reaction from Compounds $\mathbf{1 0}$ and $\mathbf{1 1} a$
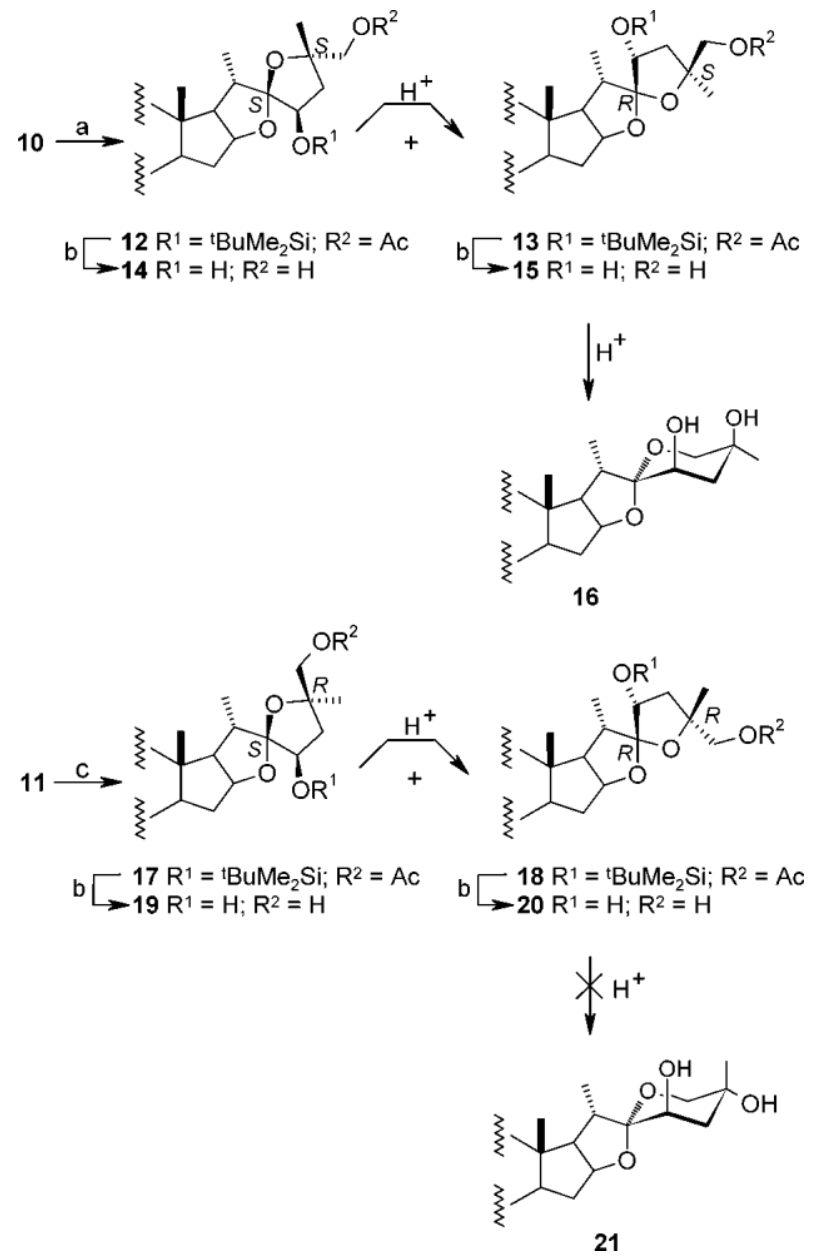

${ }^{a}$ Reagents and conditions: (a) $\mathrm{PhI}(\mathrm{OAc})_{2}, \mathrm{I}_{2}$, cyclohexane, $h v$, $50{ }^{\circ} \mathrm{C}, 3.5 \mathrm{~h}, 83 \%$ (12/13 ratio 28:72); (b) (i) TBAF, THF, rt, (ii) $\mathrm{KOH}, \mathrm{MeOH}, \mathrm{rt}$; (c) $\mathrm{PhI}(\mathrm{OAc})_{2}, \mathrm{I}_{2}$, cyclohexane, $h v, 55^{\circ} \mathrm{C}, 7 \mathrm{~h}$, 83\% (18/19 ratio 33:67).

(22S,23R,25S)-diol 14 possesses the stereochemistry of the natural product. Compounds 14 and 19 appear to be the products of kinetic control whereas $\mathbf{1 5}$ and $\mathbf{2 0}$ are the thermodynamic products. The stability of these compounds was determined by following the evolution of the acidcatalyzed rearrangement through a C-22 oxycarbenium ion. Compound 14 was transformed into the $22 R$-isomer 15 and both $\mathbf{1 4}$ and $\mathbf{1 5}$ finally led to the dioxaspiro[4.5]decane $\mathbf{1 6}$ under prolonged hydrochloric acid treatment (Scheme 2). ${ }^{13}$ In the $25 R$ series the equilibrium is also strongly displaced from the $22 S$-diol 19 toward the more stable $22 R$-compound 20. One interesting observation was that even under prolonged reaction time neither 19 nor 20 yielded the corresponding dioxaspiro[4.5] compound 21 to any appreciable extent, in contrast to the series possessing the natural stereochemistry. These findings are in agreement with the results of a MM2 study, ${ }^{14}$ compounds 14 and 19 being the highest steric energy isomers in the respective series while compounds 15 and 20 are more stable $\left(\Delta E_{\mathbf{1 4}, 15}\right) 5 \mathrm{kcal} / \mathrm{mol}$; $\left.\left.\Delta E_{19,20}\right) 2.6 \mathrm{kcal} / \mathrm{mol}\right)$.

In conclusion, we have prepared four of eight possible isomers of the target molecule and their reactivity toward acid catalysts has been studied. The usefulness of the IHA reaction to construct the different stereoisomers of this steroidal dioxaspiro[4.4]bicyclic ring system has been demonstrated.15 The methodology is especially useful when a specific stereochemistry is required at the spirocenter since thermodynamically less stable isomers can also be obtained. Although we are conscious that the conclusions obtained from this simple model cannot be fully extrapolated to the natural products, ${ }^{16}$ it is interesting to note that the greatest acid-catalyzed reactivity corresponds to a compound with the natural stereochemistry.

Acknowledgment. This work was supported by Investigation Programmes BQU2000-0650 and BQU2001-1665 of the Direccio'n General de Investigacio'n, Spain. I.P.-M. thanks the Cooperativa Farmace'utica de Tenerife (COFARTE), Spain, for a fellowship.

Supporting Information Available: Experimental procedures and characterization for all compounds. An X-ray crystallographic file (CIF) for compounds 15 and 20. This material is available free of charge via the Internet at http://pubs.acs.org.

OL025580E

(13) The diol dissolved in $\mathrm{CHCl}_{3}$ was treated with an undetermined catalytic amount of $\mathrm{HCl}$ (some gas taken with a Pasteur pipet from the headspace of a concentrated $\mathrm{HCl}$ bottle).

(14) Molecular mechanics calculations were performed using the AMBER* all-atom force field and the GB/SA solvation model for $\mathrm{CHCl}_{3}$ as implemented in version 7.0 of the MacroModel and BatchMin packages.

(15) Shortly before submitting this Letter we became aware of the studies

by Prof. P. L. Fuchs in the ASAP section of this journal (Lee, S.; LaCour, T. G.; Lantrip, D.; Fuchs, P. L. Org. Lett. 2002, 4, 313-316. Lee, S.; Fuchs, P. L. Org. Lett. 2002, 4, 317-318) where IHA reactions are used to prepare related dioxaspirocompounds.

(16) The 14,15-double bond and the 17R-hydroxyl group may have a strong influence on the stability of the dioxaspiro ring system. 